\title{
A clinical and radiological review of 204 hiatal hernia operations
}

\author{
E. HOFFMAN and M. C. SUMNER
}

\author{
Department of Thoracic Surgery, Poole Hospital, Nunthorpe, Middlesbrough
}

\begin{abstract}
Two hundred and four patients with reflux oesophagitis and hiatal hernia were operated on by a modified Allison's technique and followed up for one to 10 years. To avoid surgical bias, the clinical and radiological findings were assessed by the co-author, a radiologist. Ages, type of hernia, symptoms, coexisting pathology, and operative technique are described. The late follow-up includes an assessment of patients' opinions of their operation and residual symptoms and a review of the radiological findings. The management of 25 patients with fibrous strictures is described. Factors preventing reflux are discussed. Current operative procedures for reflux oesophagitis are reviewed. In this series of 204 cases, five patients, that is $2.5 \%$, were surgical failures. They were all dissatisfied with their operation and their symptoms had not improved; radiologically three of them showed reflux or an irreducible hiatal hernia. This failure rate is not considered unreasonable and the modified Allison's procedure is therefore recommended for patients with reflux oesophagitis.
\end{abstract}

There is still a wide divergence of opinion about the management of hiatal hernia and gastrooesophageal reflux. A variety of operations have been devised and discarded and there is still no standard procedure. Allison's (1951) operation was the first to be based on sound physiological principles, and one of us (E.H.) has been using a modified Allison's procedure for nearly 20 years.

\section{CLINICAL MATERIAL}

In order to evaluate this treatment we decided to review all hiatal hernia cases which were operated on by one of us (E.H.) between 1959 and 1969 with a follow-up period of one to 10 years (Table I). In all, there were 232 patients with three postoperative deaths (two from pulmonary emboli and one from uraemia). Fourteen died at home of causes not connected with their operation and 11 could not be traced or refused to attend for follow-up.

Most surgeons review their own results, and to avoid bias, in this series all patients were assessed both clinically and radiologically by the co-author (M.C.S.), a radiologist.

\section{TABLE I}

OPERATIONS FOR HIATUS HERNIA 1959-69

\begin{tabular}{l|r}
\hline Total cases & 232 \\
Died in hospital & 3 \\
Died at home & 14 \\
Untraceable or refused to attend & 11 \\
Patients reviewed & 204 \\
\hline
\end{tabular}

T A B LE II AGE DISTRIBUTION

\begin{tabular}{c|rr|rr}
\hline Age at Operation & Men & Women & Total & $\%$ \\
\cline { 1 - 3 } $20-30$ & 1 & 1 & 2 & $0 \cdot 9$ \\
$30-40$ & 11 & 5 & 16 & $7 \cdot 8$ \\
$40-50$ & 28 & 17 & 45 & $22 \cdot 1$ \\
$50-60$ & 22 & 49 & 71 & $34 \cdot 8$ \\
$60-70$ & 10 & 55 & 65 & $31 \cdot 9$ \\
$70-80$ & 2 & 3 & 5 & $2 \cdot 5$ \\
\hline Total & 74 & 130 & 204 & 100 \\
\hline
\end{tabular}

T A B LE III

TYPE OF HERNIA

\begin{tabular}{l|rr}
\hline & No. & $\%$ \\
\hline Sliding hiatus hernia & 185 & $90 \cdot 8$ \\
Paraoesophageal hernia & 6 & 2.9 \\
Recurrent hernia & 6 & $2 \cdot 9$ \\
Reflux oesophagitis (no hernia demonstrated) & 7 & 3.4 \\
\hline
\end{tabular}

AGES The series included 74 men and 130 women. Most women were in the 50-70 age group, while men were mainly between 40 and 60 (Table II). Over twothirds of the men did heavy work.

TYPE OF HERNIA In this series, sliding hiatal herniae were by far the commonest (185) (Table III). There were six paraoesophageal herniae, all of which at operation were found to be of a mixed type with the cardia above the diaphragm. Of the six recurrent herniae, four had previously been repaired through the abdomen by general surgeons and the other two by the 
author (E.H.) through a thoracic incision. Severe symptoms of reflux oesophagitis requiring surgery may also be present without a demonstrable hernia (Hiebert and Belsey, 1961); this occurred in seven patients.

SYMPтомS Patients with sliding and paraoesophageal herniae complained of symptoms of reflux oesophagitis (Table IV). The most frequent symptoms were retrosternal or epigastric pain (117) and acid regurgitation (102). Symptoms were often aggravated by change of posture (93). Sickness or vomiting were present in 70 patients. Sixty-five complained of dysphagia and of these, 25 had a fibrous stricture. Fifty-six patients complained of heartburn, 49 of indigestion, and 30 lost weight. Haematemesis occurred in 18 patients and was usually mild. Other symptoms were-dyspnoea in eight, pain between the shoulders in eight, and melaena in two cases.

T A B LE I V PREOPERATIVE SYMPTOMS

\begin{tabular}{l|cc}
\hline & No. Patients & $\%$ \\
\hline Retrosternal or epigastric pain & 117 & $57 \cdot 4$ \\
Acid regurgitation & 102 & $50 \cdot 0$ \\
Postural aggravation & 93 & $45 \cdot 6$ \\
Sickness or vomiting & 70 & $34 \cdot 3$ \\
Dysphagia & 65 & $31 \cdot 8$ \\
Heartburn & 56 & $27 \cdot 5$ \\
Indigestion (flatulence, belching or & 49 & $24 \cdot 0$ \\
epigastric discomfort) & 30 & $14 \cdot 7$ \\
Loss of weight & 18 & $8 \cdot 8$ \\
Haematemesis & 8 & $3 \cdot 9$ \\
Dyspnoea & 8 & $3 \cdot 9$ \\
Pain between shoulders & 2 & $0 \cdot 9$ \\
Melaena & & \\
\hline
\end{tabular}

T A B L E V

ANAEMIA ON ADMISSION

\begin{tabular}{|c|c|c|}
\hline $\mathrm{Hb} \%$ & No. Patients & $\%$ \\
\hline $\begin{array}{l}30-40 \\
40-50 \\
50-60 \\
60-70\end{array}$ & $\begin{array}{l}5 \\
1 \\
4 \\
7\end{array}$ & $\begin{array}{l}2.50 \\
0.49 \\
1.90 \\
3.40\end{array}$ \\
\hline
\end{tabular}

Preoperative anaemia was present in 17 patients (Table V). Windsor and Collis (1967) stated that anaemia occurred three times as often in paraoesophageal herniae as in the sliding variety. In our patients with anaemia, one had a paraoesophageal hernia and 16 had herniae of the sliding variety.

Two of the paraoesophageal herniae were admitted with acute obstructive symptoms and were operated on after the acute stage had subsided. These herniae should be repaired, even if symptom free, because of the danger of strangulation (Hoffman, 1968).

In two of the six recurrent herniae there was no postoperative relief of symptoms and the operation must be presumed to have been ineffective.

OTHER PATHOLOGY Opinions vary about how often peptic ulceration occurs in patients with hiatal
T A B L E V I

PREVIOUS OPERATIONS

Appendicectomy
Hysterectomy
Varicose veins
Uterine prolapse
Cholecystectomy
Partial gastrectomy or gastroenterostomy
Inguinal hernia
Thyroidectomy
Oophorectomy
Haemorrhoidectomy

herniae. Casten, Bernhang, Nach, and Spinzia (1963) stated that duodenal ulceration was present in $50 \%$ of their patients with symptomatic hiatal herniae. Brain (1966), however, found an incidence of only $4 \cdot 2 \%$, and $\widehat{~}$ Collis (1970) had an incidence below $6.5 \%$. In our series the preoperative barium meal showed only one patient with a duodenal ulcer although six others stated that they had had peptic ulceration in the past.

Twelve patients had a blood pressure of $200 / 110 \mathrm{mmHg}$ or over. Eighteen patients had chronic $\vec{\varphi}$ bronchitis and four suffered from ischaemic heart $\omega$ disease. Severe kyphoscoliosis was present in four cases.

Some patients had had previous surgical treatment (Table VI).

\section{OPERATIVE TECHNIQUE}

Preoperative oesophagoscopy was carried out in all cases to assess the degree of oesophagitis and to exclude other pathology.

A modified Allison's repair was performed on all patients. The chest was opened through the seventh interspace. Early in the series two to three intercostal nerves were divided to prevent postoperative pain, but this was abandoned because of troublesome numbness and bulging of the left epigastrium.

The oesophagus was mobilized up to the inferior pulmonary vein or higher to prevent tension after reduction of the cardia below the $\frac{T}{0}$ diaphragm. Care was taken not to divide any vagal fibres during dissection of the oesophagus $\mathcal{N}$ because vagal damage was thought to be the cause $N$ of transient diarrhoea in three of our patients.

A finger of the left hand was passed through $\omega$ a short diaphragmatic incision and through the hiatus into the hernial sac. The sac was not divided, as in Allison's repair, but was left intact and a $\stackrel{\infty}{\rightarrow}$ purse string suture was put around its periphery close to but not including the oesophagus. The purse string suture and a tape around the oeso- $\mathbb{D}$

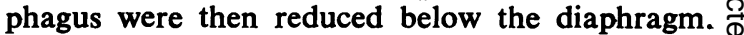
The purse string was then tied and stitched to the undersurface of the diaphragm. Two or three interrupted stitches were usually added to re- 8 inforce the fixation of the sac to the diaphragm. 
After the limbs of the right crus were dissected, the diaphragmatic reflection of the pericardium was mobilized. The first retro-oesophageal suture approximating the limbs of the crus included a good bite of the tendinous diaphragm medially.

In closing the diaphragmatic incision care was taken to include both the pleural and peritoneal layers. The object of this was to prevent herniation and strangulation of the stomach through the diaphragmatic incision, as described by Effler (1965).

Allison's technique was followed except for two modifications. First, the sac was preserved and fixed to the diaphragm with a purse string, because we believe that this is a more secure method of fixation of the cardia below the diaphragm. Secondly, in our opinion the inclusion of the tendinous portion of the diaphragm in the first retro-oesophageal suture plays an important part in preventing recurrence.

\section{POSTOPERATIVE COMPLICATIONS}

The most frequent postoperative complication was pulmonary embolism which occurred in 12 of our patients. In recent years all patients except the elderly have been given anticoagulants from the fourth postoperative day, although their value in preventing and treating postoperative thrombosis and embolism remains controversial.

Persistent gastric dilatation was present in three patients. One of these had a past history of pyloric stenosis; in the other two no obvious pathology could be found. One of these had such severe dilatation that laparotomy became necessary. Nothing abnormal was found, but the dilatation persisted in spite of a gastroenterostomy. The patient's condition improved only after large doses of potassium, although the serum electrolytes were within normal limits.

Two patients had erythema due to anticoagulants, and two developed auricular fibrillation. In another case the thoracotomy incision broke down and the wound had to be resutured.

Incisional pain is a well-recognized complication of low thoracic incisions. It occurred in 26 of our patients but was usually of a transient nature. In two patients it was severe enough to require intercostal neurectomy.

\section{LATE FOLLOW-UP}

All patients attended personally for follow-up. They were asked how satisfied they were with their operation and were questioned about any symptoms. A barium meal was done and was compared with the pre- and postoperative barium films. We did not do special studies such as intraluminal pressure and $\mathrm{pH}$ recordings.

PATIENTS' ASSESSMENT Of the 204 patients, 155 $(75.9 \%)$ were completely satisfied, $37(18.1 \%)$ were partially satisfied, and $12(5.9 \%)$ were dissatisfied with their operation (Table VII). The proportion of those completely satisfied and partially satisfied was similar in both sexes; there were, however, relatively more dissatisfied women than men.

T A B L E VII

PATIENT'S ASSESSMENT OF RESULT

\begin{tabular}{l|cc|cc}
\hline & Men & Women & Total & $\%$ \\
\cline { 2 - 3 } $\begin{array}{l}\text { Completely satisfied } \\
\text { Partially satisfied }\end{array}$ & 58 & 97 & 155 & $75 \cdot 9$ \\
Dissatisfied & 14 & 23 & 37 & $18 \cdot 1$ \\
& 2 & 10 & 12 & $5 \cdot 9$ \\
\hline
\end{tabular}

RESIDUAL SYMPTOMS One hundred and thirty-six (66.7\%) patients had no symptoms of oesophagitis (Table VIII). In $61(29.9 \%)$ symptoms were either mild or moderate. Seven $(3.4 \%)$ patients said that their symptoms had not improved. Symptoms of oesophagitis were thus either cured or improved in 197 (96.6\%).

In 15 of the 49 partially satisfied and dissatisfied patients symptoms were due to coincidental pathological conditions, such as coronary thrombosis, hypertension, asthmatic bronchitis, osteoarthritis of the spine, and psychosis.

RADIOLOGICAL FINDINGS The technique employed by radiologists to demonstrate reflux or a hernia varies. In this series patients were examined in the upright position while drinking barium, and they were then tilted into the Trendelenburg posi-

T A B L E V I I I

RESIDUAL SYMPTOMS OF OFSOPHAGITIS AND PATIENT'S ASSESSMENT OF RESULT

\begin{tabular}{|c|c|c|c|c|c|c|c|c|}
\hline \multirow[b]{2}{*}{ Symptoms of oesophagitis } & \multicolumn{2}{|c|}{ Completely Satisfied } & \multicolumn{3}{|c|}{ Partially Satisfied } & \multicolumn{3}{|c|}{ Dissatisfied } \\
\hline & None & Mild & None & Mild or improved & No change & None & Improved & No change \\
\hline & 121 & 34 & 10 & 24 & 3 & 5 & 3 & 4 \\
\hline
\end{tabular}


T A B LE IX

RESIDUAL REFLUX AND HERNIA AND ITS RELATION TO PATIENT'S ASSESSMENT AND SYMPTOMS OF OESOPHAGITIS

\begin{tabular}{|c|c|c|c|c|c|c|c|}
\hline \multirow{2}{*}{ Symptoms } & \multicolumn{2}{|c|}{ Completely Satisfied } & \multicolumn{2}{|c|}{ Partially Satisfied } & \multicolumn{2}{|c|}{ Dissatisfied } & \multirow[t]{2}{*}{ Total } \\
\hline & None & Mild & Improved & No Change & Improved & No Change & \\
\hline $\begin{array}{l}\text { Reflux only } \\
\text { Reflux + hiatus hernia (in Trendelenburg position) } \\
\text { Refiux + irreducible hiatus hernia }\end{array}$ & $\begin{array}{l}7 \\
1 \\
0\end{array}$ & $\begin{array}{l}4 \\
4 \\
0\end{array}$ & $\begin{array}{l}1 \\
1 \\
0\end{array}$ & $\begin{array}{l}\mathbf{0} \\
1 \\
0\end{array}$ & $\begin{array}{l}\mathbf{0} \\
\mathbf{0} \\
\mathbf{1}\end{array}$ & $\begin{array}{l}1 \\
0 \\
1\end{array}$ & $\begin{array}{r}13 \\
7 \\
2\end{array}$ \\
\hline Total & 8 & 8 & 2 & 1 & 1 & 2 & $22(10 \cdot 8 \%)$ \\
\hline
\end{tabular}

T A B L E X

LATE ABNORMAL BARIUM MEAL APPEARANCES AND RELATION TO PATIENT'S ASSESSMENT OF RESULT

\begin{tabular}{|c|c|c|c|c|c|}
\hline & Completely Satisfied & Partially Satisfied & Dissatisfied & Total & $\%$ \\
\hline $\begin{array}{l}\text { Reflux or refiux and hernia } \\
\text { Delay of passage of barium due to: } \\
\text { (a) spasm and incoordination of movements } \\
\text { (b) residual stricture } \\
\text { Diverticulum of oesophagus or stomach } \\
\text { Partial torsion of stomach } \\
\text { Gastric or duodenal ulcer } \\
\text { Partial gastrectomy (Billroth I) }\end{array}$ & $\begin{array}{r}17 \\
5 \\
3 \\
7 \\
4 \\
1 \\
2\end{array}$ & $\begin{array}{l}3 \\
\mathbf{4} \\
\mathbf{1} \\
\mathbf{1} \\
\mathbf{3} \\
\mathbf{1}\end{array}$ & $\begin{array}{l}2 \\
2 \\
0 \\
1 \\
0 \\
0 \\
1\end{array}$ & $\begin{array}{r}22 \\
11 \\
4 \\
9 \\
7 \\
2 \\
3\end{array}$ & $\begin{array}{l}10 \cdot 8 \\
5 \cdot 4 \\
1 \cdot 9 \\
4 \cdot 4 \\
3 \cdot 4 \\
0 \cdot 9 \\
1 \cdot 4\end{array}$ \\
\hline
\end{tabular}

tion lying supine. They were asked to turn unaided on to their right side and told to cough several times in quick succession and to swallow. If the slightest reflux was seen they were then asked to raise their legs. After films were taken in the right Trendelenburg position patients were told to turn unaided on to their back and then to the left side. Films were then taken in the left oblique Trendelenburg position.

Postoperative reflux was seen in 22 patients (Table IX). In 13 of these reflux alone was present, in the remaining nine a hiatal hernia was also found. Seven of the hiatal herniae appeared only in the Trendelenburg position and two were irreducible. The demonstration of reflux alone or reflux with a reducible hiatal hernia did not affect patients' opinions of their operation; 16 of the 22 patients with reflux were completely satisfied. Mild or moderate symptoms, however, were present in 11 of the 22 cases. Two patients with reflux and an irreducible hiatal hernia were both dissatisfied and their symptoms persisted. Although it is not known why some people with reflux develop oesophagitis and others do not, it is likely that the amount of reflux matters. The type of reflux is also important. Reflux of bile leads to a more severe oesophagitis than that with acid pepsin regurgitation (Moffat and Berkas, 1965). This was observed in three patients who developed a severe oesophagitis following a Billroth I gastrectomy.
All 22 patients who had reflux or herniation $\frac{0}{\mathbb{2}}$ developed it either immediately postoperatively or $\stackrel{\circ}{\overrightarrow{2}}$ during the first two years.

In 15 patients there was delayed passage of barium at the lower end of the oesophagus (Table $\mathrm{X})$. In four this was due to a residual stricture. In 11 cases there was spasm and incoordination of the oesophageal wall. This has been ascribed $\frac{0}{0}$ to reflux oesophagitis by Olsen and Schlegel ${ }_{0}^{\times}$ (1965), but in our cases reflux could be demon- 3 strated in only two patients. Of the remaining nine, abnormal peristalsis in three patients was thought to be due to low oesophageal diverticula 0 and in the other six no pathology was found although the hiatal repair might have been too tight.

Of the nine diverticula, seven were oesophageal $\tilde{N}$ and two gastric. The oesophageal diverticula were $N$ small and found just above the diaphragm. Seven $N$ patients had partial torsion of the stomach; three of these had originally had large paraoesophageal herniae.

Peptic ulceration was rare at follow-up; only one patient had a gastric ulcer and one a duo. denal, although postoperatively peptic ulceration was seen in seven patients.

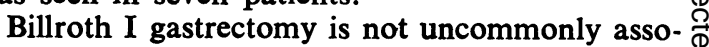
ciated with reflux oesophagitis (Windsor, 1964). Three of our patients had already had a Billroth I gastrectomy. In two of these, reflux symptoms o appeared in the early postoperative period. One 
had a prolonged dilatation of the gastric remnant postoperatively, which may have facilitated reflux of bile previously described by Toye and Williams (1965).

\section{STRICTURES}

Patients with a hiatal hernia and a fibrous stricture present a difficult problem. Twenty-five $(12.3 \%)$ of the 204 patients had a tight fibrous stricture secondary to reflux oesophagitis (Table XI). They all complained of severe dysphagia; 10 found it difficult even to drink. In 10 the stricture was at mid-oesophageal level, in three between 25 and $28 \mathrm{~cm}$ from the lower teeth, and in seven between 32 and $35 \mathrm{~cm}$. They all needed preoperative dilatations: in 16 one dilatation was enough, while the remaining nine required two or more dilatations.

\section{T A B L E X I}

OESOPHAGEAL STRICTURE (25 PATIENTS)

\begin{tabular}{l|c|c|c}
\hline & $\begin{array}{c}\text { Completely } \\
\text { Satisfied }\end{array}$ & $\begin{array}{c}\text { Partially } \\
\text { Satisfied }\end{array}$ & Dissatisfied \\
\cline { 2 - 4 } & 22 & 3 & 0 \\
\hline $\begin{array}{c}\text { Symptoms: Mild dysphagia } \\
\text { Barium meal: } \\
\begin{array}{c}\text { Constriction of the } \\
\text { oesophagus and delay of } \\
\text { barium }\end{array}\end{array}$ & 6 & 1 & 0 \\
\begin{tabular}{c} 
Free reflux \\
\hline
\end{tabular} & 1 & 1 & 0 \\
\hline
\end{tabular}

In a patient with a stricture a good result can be achieved by dilatation and replacement of the intra-abdominal oesophagus below the diaphragm. This may not always be easy as oesophageal shortening is not uncommonly present. Of 25 patients receiving this treatment, 22 were completely satisfied (although six of them still had slight residual dysphagia) and three were partially satisfied. It was unsuccessful in one patient who had a colonic interposition at another hospital and is not included.

Results with dilatation and repair are better if the stricture is in the lower oesophagus. The stricture was situated at mid-oesophageal level in six of the seven patients who had residual dysphagia.

Four of the 25 patients needed postoperative dilatations. Dilatation in fibrous strictures need not be a hazardous procedure (Skinner and Belsey, 1967). The 25 patients in this series had 59 dilatations without any complications. One patient with a stricture and a hiatal hernia was perforated during dilatation. The perforation was repaired but she refused further surgery and is not included.

\section{DISCUSSION}

It has been accepted in recent years that there are two main factors in the control of reflux: (a) a normal anatomical position of the intraabdominal segment of the oesophagus, and $(b)$ an effective internal oesophageal sphincter. No operation can restore a damaged sphincter and surgical techniques are designed to restore and maintain the normal anatomy of the hiatal region.

Recently there has been a good deal of controversy about the importance of the internal oesophageal sphincter in the prevention of reflux. Some authors (Lind, Warrian, and Wankling, 1966 ; Haddad, 1970 ; Cohen and Harris, 1971) believe that the presence or absence of oesophagitis depends only on the effectiveness of the sphincter irrespective of its position. They have provided some evidence to prove that the presence or absence of hiatal hernia is of no significance and infer that surgery is of no value in this condition.

Others (Clagett, 1966; Skinner and Belsey, 1967; Collis, 1970; Ellis, 1971) believe that the internal oesophageal sphincter functions best when all anatomical factors in the region of the gastrooesophageal junction are normal. The importance of restoring a normal anatomy at the hiatal region has been confirmed by numerous surgeons reporting a high operative success rate in symptomatic hiatal herniae over the past two decades. There is also experimental evidence to confirm this view. Meiss (1963) showed that less intragastric pressure is required to overcome the sphincter if it is located above the diaphragm than in the abdomen. Baue and Hoffer (1967) also found in experiments on dogs that the internal oesophageal sphincter works less efficiently if placed above the diaphragm.

On present evidence surgery has a definite although limited role in the management of hiatal hernia. Radiological demonstration of a hiatal hernia (except for large para-oesophageal herniae) is not an indication for operation. Raphael, Ellis, Carlson, and Andersen (1965) reported that of 6,571 hiatal herniae only $4 \%$ had surgical treatment. In Palmer's (1968) series, operation was carried out on $3.8 \%$ of 1,011 patients. In our series we have accepted for operation only those patients who had such severe symptoms that they were not prepared to continue with conservative measures. Certain complications of reflux oesophagitis are indications for surgery. These are fibrous strictures, bleeding giving rise to severe anaemia, and obstructed or strangulated herniae. 
The first operation for reflux oesophagitis designed to restore normal anatomical and physiological conditions was described by Allison in 1951. The popularity of this procedure has declined in recent years because of reported high recurrence rates (Raphael et al., 1965; Pearson and Gray, 1967; Hill, 1967; Urschel and Paulson, 1967). In the authors' view, Allison's concept of repair remains valid and his procedure has been used in this series with slight modifications.

The two currently fashionable operative techniques are Nissen's (1961) fundoplication, where the fundus of the stomach is wrapped around the oesophagus, and Belsey's Mark IV repair (Skinner and Belsey, 1967) where the oesophagus is invaginated into the stomach. Nissen and Rossetti (1965) found that $10 \%$ of their patients had difficulty in eructation and suffered from gastric distension. In both operations stitches are inserted into an often friable oesophageal wall which may lead to serious complications. Nissen and Rossetti (1965) reported four deaths due to peritonitis, while Skinner and Belsey (1967) observed five patients with oesophageal necrosis (two of whom died) following the Mark IV repair. Orringer, Skinner, and Belsey (1972), reviewing hiatal hernia repairs carried out by the Mark IV procedure, reported a recurrence rate of $12 \%$ in patients followed up for from three to 10 years.

It is difficult to make valid comparisons of the efficacy of different surgical procedures. No single method of assessment-radiological, relief of symptoms or patient's opinion of the operationis a reliable guide. Radiological demonstration of reflux or a hernia in an asymptomatic patient is of no great clinical significance. To the patient, all that matters is that he be cured or relieved of his symptoms. The interpretation of symptomatic relief is personal and varies with time, and the patient's overall opinion of the operative result may be influenced by other coincidental diseases. Five of our 12 dissatisfied patients had no oesophageal symptoms but suffered from a variety of other diseases.

Of our 204 patients with reflux oesophagitis and hiatal herniae repaired by a modified Allison's procedure, only five $(2.5 \%)$ were surgical failures. These were all dissatisfied, four because their symptoms had not improved and one because she developed dysphagia with oesophageal spasm. Three of these patients also showed reflux or an irreducible hiatal hernia. A failure rate of $2.5 \%$ is not unreasonable and this operative procedure can therefore be recommended in patients with severe symptoms of reflux oesophagitis.

\section{REFERENCES}

Allison, P. R. (1951). Reflux oesophagitis, sliding hiataĒ hernia, and the anatomy of repair. Surg. Gynec. Obstet. 92, 419.

Baue, A. E., and Hoffer, R. E. (1967). The effects of experi® mental hiatal hernia and histamine stimulation on the intrinsic esophageal sphincter. Surg. Gynec. Obstet., 125, 791.

Brain, R. (1966). Peptic strictures of the oesophagus associated with duodenal ulcer and operations for its relief. $\omega$ Proc. roy. Soc. Med., 59, 929.

Casten, D. F., Bernhang, A., Nach, R. J., and Spinzia, J户্থ (1963). A physiological basis for the surgical treatmeni of sliding esophageal hiatus hernia. Surg. Gynec. Obstet. $117,87$.

Clagett, O. T. (1966). Present concepts regarding the surgical treatment of oesophageal hiatal hernia. Ann. roy. Coll. Surg. Engl., 38, 195.

Cohen, S., and Harris, L. D. (1971). Does hiatus hernia affectcompetence of the gastroesophageal sphincter? Nens Engl. J. Med., 284, 1053.

Collis, J. L. (1970). An appraisal of the methods for treating hiatus hernia and its complications. Ann. roy. Coll Surg. Engl., 46, 338.

Effler, D. B. (1965). Allison's repair of hiatal hernia: late complication of diaphragmatic counterincision and technique to avoid it. J. thorac. cardiovasc. Surg., 49, 669.5

Ellis, F. H. Jr. (1971). Gastroesophageal reflux. Indications for fundoplication. Surg. Clin. N. Amer., 51, 575.

Haddad, J. K. (1970). Relation of gastroesophageal reflux toळ yield sphincter pressures. Gastroenterology, 58, 175.

Hiebert, C. A., and Belsey, R. (1961). Incompetence of the gastric cardia without radiologic evidence of hiatal hernia. J. thorac. cardiovasc. Surg., 42, 352.

Hill, L. D. (1967). An effective operation for hiatal hernia an eight year appraisal. Ann. Surg., 166, 681.

Hoffman, E. (1968). Strangulated diaphragmatic hernia Thorax, 23, 541 .

Lind, J. F., Warrian, W. G., and Wankling, W. J. (1966)을 Responses of the gastroesophageal junctional zone to increases in abdominal pressure. Canad. J. Surg., 9, 32.

Meiss, J. H. (1963). The mechanism of the cardia, an experi mental study. Arch. chir. neerl., 15, 19.

Moffat, R. C., and Berkas, E. M. (1965). Bile esophagitis. Arch. Surg., 91, 963.

Nissen, R. (1961). Gastropexy and fundoplication in surgical treatment of hiatal hernia. Amer.J. dig. Dis., 6, 954. O - and Rossetti, M. (1965). Surgery of hiatal and othern diaphragmatic hernias. J. int. Coll. Surg., 46, 663.

Olsen, A. M., and Schlegel, J. F. (1965). Motility disturbances caused by esophagitis. J. thorac. Surg., 50, 607.

Orringer, M. B., Skinner, D. B., and Belsey, R. H. R. (1972)@ Long-term results of the Mark IV operation for hiatalo hernia and analyses of recurrences and their treatment. J. thorac. cardiovasc. Surg., 63, 25.

Palmer, E. D. (1968). The hiatus hernia-esophagitis-esophageal stricture complex. Amer. J. Med., 44, 566.

Pearson, J. B., and Gray, J. G. (1967). Oesophageal hiatus hernia: long-term results of the conventional thoracic operation. Brit. J. Surg., 54, 530.

Raphael, H. A., Ellis, F. H., Carlson, H. C., and Andersen, H. A. (1965). Surgical repair of sliding esophageal hiata응 hernia: long-term results. Arch. Surg., 91, 228. 
Skinner, D. B., and Belsey, R. H. R. (1967). Surgical management of esophageal reflux and hiatus hernia: long-term results with 1,030 patients. J. thorac. cardiovasc. Surg., 53, 33.

Toye, D. K. M., and Williams, J. A. (1965). Post-gastrectomy bile vomiting. Lancet, 2, 524.
Urschel, H. C., and Paulson, D. L. (1967). Gastroesophageal reflux and hiatal hernia: complications and therapy. $J$. thorac. cardiovasc. Surg., 53, 21.

Windsor, C. W. O. (1964). Gastro-oesophageal reflux after partial gastrectomy. Brit. med. J., 2, 1233.

and Collis, J. L. (1967). Anaemia and hiatus hernia: experience in 450 patients. Thorax, 22, 73. 